\title{
Neurocognitive functioning in school-aged cystinosis patients
}

\author{
M. T. P. Besouw - G. M. Hulstijn-Dirkmaat • R. E. A. van der Rijken • \\ E. A. M. Cornelissen • C. M. van Dael • J. Vande Walle • M. R. Lilien • \\ E. N. Levtchenko
}

Received: 14 September 2009 /Revised: 11 May 2010 /Accepted: 26 July 2010 / Published online: 3 September 2010

(C) The Author(s) 2010. This article is published with open access at Springerlink.com

\begin{abstract}
Introduction Cystinosis is an autosomal recessive disorder leading to intralysosomal cystine accumulation in various tissues. It causes renal Fanconi syndrome and end stage renal failure around the age of 10 years if not treated with cysteamine. Children with cystinosis seem to have a normal intelligence but frequently show learning difficulties. These
\end{abstract}

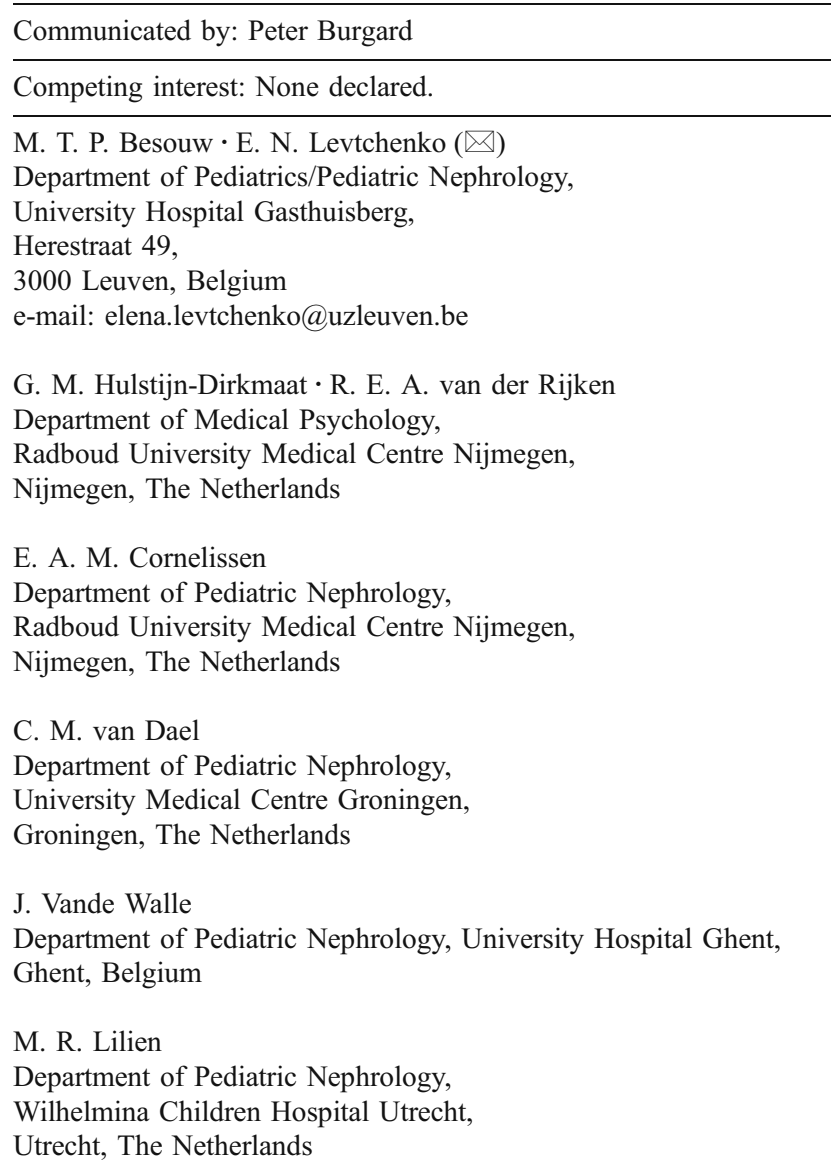

problems may be due to specific neurocognitive deficits rather than impaired renal function. Whether cysteamine treatment can improve cognitive functioning of cystinosis patients is thus far unknown. We aim to analyze neurocognitive functioning of school-aged cystinosis patients treated with cysteamine in order to identify specific deficits that can lead to learning difficulties.

Patients and methods Fourteen Dutch and Belgian schoolaged cystinosis patients were included. Glomerular filtration rate was estimated using the Schwartz formula. Children were tested for general intelligence, visual-motor integration, inhibition, interference, sustained attention, accuracy, planning, visual memory, processing speed, motor planning, fluency and speed, and behavioural and emotional functioning using standardized methods.

Results Glomerular filtration rate ranged from 22 to $120 \mathrm{ml} \mathrm{min}^{-1} 1.73 \mathrm{~m}^{-2}$. Median full-scale intelligence was below the average of a normal population (87, range 60-132), with a discrepancy between verbal (median 95, range 60-125) and performance (median 87, range 65130) intelligence. Over $50 \%$ of the patients scored poorly on visual-motor integration, sustained attention, visual memory, planning, or motor speed. The other tested areas showed no differences between patients' and normal values.

Conclusion Neurocognitive diagnostics are indicated in cystinosis patients. Early recognition of specific deficits and supervision from special education services might reduce learning difficulties and improve school careers.
Abbreviations
GFR Glomerular filtration rate
IQ Intelligence quotient
VMI Visual motor integration
CBCL Child behavior checklist 


\section{Introduction}

Cystinosis is a rare autosomal recessive disorder caused by mutations in the CTNS gene, encoding the lysosomal cystine carrier cystinosin. This results in intralysosomal accumulation of the amino acid cystine (Town et al. 1998). The most frequent and severe infantile form has an incidence of 1 case in every 100,000 to 200,000 live births. Children present with renal Fanconi syndrome, mostly during the first year of life. This generalized proximal tubular damage progresses towards end stage renal disease around the age of 10 years. Extra-renal organs are also affected, including eyes, endocrine organs, muscles, and central nervous system. Cystinosis is treated by administration of the cystine-depleting agent cysteamine, which slows down the progression of renal failure and protects extra-renal organs (Gahl et al. 2002).

Previously it was believed that since children with cystinosis have a normal intelligence, no learning difficulties should be expected. Moreover, poor school results were often explained by renal disease or seen as a consequence of a chronic illness and its treatment. In 1988, however, it was demonstrated that cystinosis patients have neurocognitive impairments that cannot be attributed to their decreased renal function (Trauner et al. 1988). Despite a normal intelligence, deficits in visual information processing and tactile recognition processing have been reported. As a result, poor school performances, in particular for spelling and arithmetic, have been found (Ballantyne et al. 1997; Colah and Trauner 1997; Spilkin et al. 2007; Williams et al. 1994; Wolff et al. 1982).

The aim of this study was to analyze neurocognitive functioning in Dutch and Belgian school-aged cystinosis patients treated with cysteamine starting from an early age in order to identify specific deficits that might lead to learning difficulties and to evaluate the influence of cysteamine treatment. Furthermore, we analyzed the effect of different CTNS mutations on neurocognitive functioning.

\section{Patients and methods}

Fourteen school-aged cystinosis patients (age 6-17 years), treated in three Dutch and two Belgian hospitals, were included. Cystinosis was diagnosed at a mean age of 1 year and 10 months, and cysteamine treatment was started immediately thereafter and monitored by measuring white blood cell (WBC) cystine levels every 2-4 months. The diagnosis was confirmed by mutational analysis of the CTNS gene in 13/14 patients. "Whole life" mean WBC cystine levels were calculated from all measurements after the onset of cysteamine treatment. The glomerular filtration rate (GFR) at the moment of testing was estimated using the Schwartz formula (Schwartz et al. 2009). Patients were scheduled for neurocognitive assessment after written informed consent was obtained from parent(s) and patients $\geq 12$ years of age. A standard test battery was completed by all patients. These tests were administered by a trained psychology assistant, who was supervised by a research psychologist. The study was approved by the institutional review board of the Radboud University Medical Centre.

General intelligence

\section{WISC-III}

The Wechsler Intelligence Scale for Children, 3rd edition (WISC-III) is a standardized method to test the intelligence quotient (IQ) in children 6-16 years of age (Kort et al. 2002; Wechsler 1991). Patient 8 (17.4 years of age) completed the Wechsler Adult Intelligence Scale (WAIS). Three general measures were derived: full-scale IQ, verbal IQ, and performance IQ.

Neurocognitive function

\section{$V M I$}

The Developmental Test of Visual-Motor Integration (VMI) measures visual-motor integration skills, indicated by the ability to copy increasingly complex geometric forms (Beery 1997).

\section{Stroop Color-Word Interference Test}

The Stroop Color-Word Interference Test measures inhibition and interference (e.g., the ability to suppress a habitual response in support of an unusual one) (Hammes 1978). It is divided into word reading (reading color names printed in black) and color naming (naming the print colors of colored bars and naming the print colors of color names when both are not the same). The latter measures the ability to say the print color while suppressing the response to say the color name, which is an interference test. Although this test was originally developed for adults, standardized age norms (7-12 years) for the Dutch population were available and used. The test was not performed in patient 2 , since she was $<7$ years of age and in patients 4 and 8 , since they were $>12$ years of age.

\section{Bourdon-Vos Test}

The Bourdon-Vos Test measures sustained attention and accuracy (Vos 1998). Children had to cross out all groups of four dots on a page filled with groups of three, four, and 
five dots. Scores for both speed and accuracy were normed and evaluated. Patient 13 was too tired to complete the test.

\section{Rey-Osterrieth Complex Figure}

Rey's figure was administered to measure planning (organization) and visual memory (Bernstein and Waber 1996). Children had to copy a complex figure and draw it from memory immediately thereafter (immediate recall) and after a delay of $20 \mathrm{~min}$ (delayed recall). Since the test has a norm only for children up to 14 years of age, it was not performed in patients 4 and 8 .

\section{Computerized drawing task}

A computerized drawing task was administered to evaluate processing speed, motor planning, motor fluency, and motor speed (Schoemaker et al. 1994). Drawing movements were digitally recorded by a digitizing tablet and a wireless electronic pen. Processing speed was indicated by mean reaction time, motor planning by mean duration of pauses between small and large elements, motor fluency by mean number of velocity peaks, and motor speed by mean drawing speed $(\mathrm{cm} / \mathrm{s})$.

Behavioral and emotional functioning

\section{$C B C L$}

The Child Behavior Checklist (CBCL) is used to recognize problems of behavioral and emotional functioning (Achenbach 1991). Three parallel versions of the Dutch CBCL were administered: a parent's version, a patient's version for children $\geq 12$ years of age, and a teacher's version (Verhulst et al. 1996, 1997a, b). Scores indicating internalizing, externalizing, and total problems were derived.

\section{Statistical analysis}

Correlations between full-scale, verbal, and performance IQ and GFR and between full-scale, verbal, and performance IQ and "whole life" WBC cystine levels were estimated using the Spearman rank correlation method. The general intelligence measures of patients having a homozygous $57 \mathrm{~kb}$ deletion of the CTNS gene were compared with those of patients with other mutations using the MannWhitney $U$ tests. Values were considered statistically significant at $P<0.05$.

\section{Results}

Data on GFR, WBC cystine levels, CTNS gene mutations, and educational levels of the parents are shown in Table 1.
Eight patients were homozygous for the large $57 \mathrm{~kb}$ deletion in the CTNS gene, and five patients were heterozygous and had the $57 \mathrm{~kb}$ deletion combined with another mutation; DNA analysis was not performed in patient 13 . GFR ranged from 22 to 120 (normal $\geq 90$ ) $\mathrm{ml}$ $\min ^{-1} 1.73 \mathrm{~m}^{-2}$, seven patients had a decreased GFR of $<90 \mathrm{ml} \mathrm{min}{ }^{-1} 1.73 \mathrm{~m}^{-2}$, and patient 4 had a functioning renal graft. Mean WBC cystine levels were within the range of healthy carriers $(0.26-0.86 \mathrm{nmol}$ half-cystine $/ \mathrm{mg}$ protein) in $5 / 14$ patients, indicating adequate cysteamine treatment (Table 1). Results of the neurocognitive tests are shown in Table 2. Scores were defined as average, poor, or low according to the instructions in the test manuals. In all tests except for Rey's figure, a score of 1 standard deviation (SD) or more above or below the average was considered to be significant. In Rey's figure, scores were qualified as poor if below or equal to the 10th percentile and good if above or equal to the 90th percentile. The WISC-III, WAIS, and VMI have an average score of 100, with an SD of 15.

\section{General intelligence}

Median full-scale IQ was 87 (range 60-132), median verbal IQ 87 (range 60-125), and median performance IQ 95 (range 65-130). Five patients $(36 \%)$ scored $\geq 1$ SD below the average for full-scale IQ. In five patients $(36 \%)$, the verbal IQ was $\geq 1$ SD higher than the performance IQ, none of the patients had a significantly better performance IQ compared to the verbal IQ.

\section{Neurocognitive functions}

All 14 children completed the VMI. Seven children (50\%) had a poor performance ( $\leq 85$ points), and none had a good performance ( $\geq 115$ points) on this test.

The Stroop Color-Word Interference Test was performed in 11/14 patients and showed no abnormalities: 5 children (45\%) had an average performance, 3 children (27\%) had a poor performance, and 3 children (27\%) had a good performance.

The Bourdon-Vos Test was performed in 13/14 patients. Only four patients (31\%) showed a normal sustained attention, while the other nine patients $(69 \%)$ showed a delayed sustained attention. There were no evident problems in accuracy: six children (46\%) had a good performance, five children (38\%) had a poor performance.

The Rey-Osterrieth Complex Figure was completed by 12/ 14 children. Four patients $(33 \%)$ had a score of poor on planning (organization), only one patient ( $8 \%$ ) had a score of good on planning items. Three patients $(25 \%)$ had a score of poor on visual memory, none had a score of good on this item.

The computerized drawing task was completed by all 14 children. Two patients (14\%) had a good score on processing speed, and four patients $(29 \%)$ had a poor score 
Table 1 Clinical data on the patients and educational levels of the parents

\begin{tabular}{|c|c|c|c|c|c|c|c|c|c|}
\hline Patient & $\begin{array}{l}\text { Age } \\
\text { (years) }\end{array}$ & Sex & $\begin{array}{l}\text { Age at onset } \\
\text { of cysteamine } \\
\text { therapy (years) }\end{array}$ & $\begin{array}{l}\text { DNA analysis } \\
\text { of } C T N S \text { gene }\end{array}$ & $\begin{array}{l}\text { Renal } \\
\text { status }\end{array}$ & $\begin{array}{l}\text { GFR }\left(\mathrm{ml} \min ^{-1}\right. \\
\left.1.73 \mathrm{~m}^{-2}\right)\end{array}$ & $\begin{array}{l}\text { Mean (SD) cystine } \\
\text { levels }{ }^{\mathrm{a}} \text { (nmol half- } \\
\text { cystine/mg protein) }\end{array}$ & $\begin{array}{l}\text { Educational } \\
\text { background } \\
\text { father }\end{array}$ & $\begin{array}{l}\text { Educational } \\
\text { background } \\
\text { mother }\end{array}$ \\
\hline 01 & 10.0 & $\mathrm{~F}$ & 1.2 & hom $57 \mathrm{~kb}$ del & NK & 22 & $0.98(0.46)$ & $\mathrm{U}$ & $\mathrm{U}$ \\
\hline 02 & 6.3 & $\mathrm{~F}$ & 1.3 & $\begin{array}{c}57 \mathrm{~kb} \text { del} / \mathrm{c} \cdot \operatorname{del} 18 \\
21 \mathrm{GACT}\end{array}$ & NK & 86 & $3.10(1.36)$ & $\mathrm{V}$ & $\mathrm{V}$ \\
\hline 03 & 11.1 & F & 1.10 & hom $57 \mathrm{~kb}$ del & NK & 48 & $0.74(0.64)$ & $\mathrm{V}$ & LS \\
\hline 04 & 15.5 & $\mathrm{~F}$ & 1.8 & hom $57 \mathrm{~kb}$ del & $\mathrm{Tx}$ & 72 & $0.92(0.52)$ & HV & HV \\
\hline 05 & 10.7 & M & 9.0 & $\begin{array}{c}57 \mathrm{~kb} \text { del } / \mathrm{c} .198 \\
218 \mathrm{del} 21\end{array}$ & NK & 113 & $1.10(0.36)$ & $\mathrm{V}$ & HS \\
\hline 06 & 8.4 & M & 1.3 & hom $57 \mathrm{~kb}$ del & NK & 84 & $0.86(0.54)$ & $\mathrm{V}$ & HS \\
\hline 07 & 9.2 & M & 0.9 & hom $57 \mathrm{~kb}$ del & NK & 100 & $0.96(0.52)$ & $\mathrm{V}$ & LS \\
\hline 08 & 17.4 & M & 0.6 & hom $57 \mathrm{~kb}$ del & NK & 57 & $0.84(0.40)$ & $\mathrm{HV}$ & V \\
\hline 09 & 11.8 & $\mathrm{~F}$ & 1.4 & $57 \mathrm{~kb}$ del $/ \mathrm{c} .665 \mathrm{~A}>\mathrm{G}$ & NK & 120 & $0.64(0.34)$ & $\mathrm{V}$ & $\mathrm{V}$ \\
\hline 10 & 11.8 & $\mathrm{~F}$ & 1.4 & $57 \mathrm{~kb}$ del $/ \mathrm{c} .665 \mathrm{~A}>\mathrm{G}$ & NK & 120 & $0.60(0.34)$ & $\mathrm{V}$ & $\mathrm{V}$ \\
\hline 11 & 11.3 & M & 2.8 & $57 \mathrm{~kb}$ del/c.926dup & NK & 89 & $2.03(1.28)$ & $\mathrm{V}$ & $\mathrm{HV}$ \\
\hline 12 & 7.4 & M & 0.10 & hom $57 \mathrm{~kb}$ del & NK & 112 & $4.75(2.62)$ & $\mathrm{U}$ & $\mathrm{U}$ \\
\hline 13 & 8.1 & M & 1.6 & Not done & NK & 118 & $1.56(0.68)$ & $\mathrm{V}$ & LS \\
\hline 14 & 8.6 & M & 0.10 & hom $57 \mathrm{~kb}$ del & NK & 103 & $0.96(0.74)$ & LV & LS \\
\hline
\end{tabular}

$N K$ Native kidney, $T x$ renal transplantation, $V$ vocational education, $L V$ lower vocational education, $H V$ higher vocational education, $L S$ lower secondary education, $H S$ higher secondary education, $U$ university education

${ }^{a}$ Normal values for healthy carriers: $0.26-0.86 \mathrm{nmol}$ half-cystine/mg protein

on this item. One patient (7\%) had a good score on motor planning, whereas eight patients $(57 \%)$ had a poor score on this measure. Motor fluency and motor speed showed no evident problems: three patients $(21 \%)$ showed a good score and two patients (14\%) showed a poor score on motor fluency, while two patients (14\%) showed a good score and three patients $(21 \%)$ showed a poor score on motor speed.

\section{Behavioral and emotional functioning}

Teachers reported poor school performances in two or more areas in seven patients (50\%, data not shown). The reported problem areas included arithmetic, spelling, reading comprehension, and knowledge of the world. All seven of these patients (patients 01, 03, 07, 08, 09, 10, and 14) had a risk profile for neurocognitive dysfunction, e.g., they showed a low general intelligence level or a discrepancy between verbal and performance IQ and/or a poor performance on neurocognitive tasks. No significant behavioral or emotional problems were reported by parents or patients.

\section{Statistical analysis}

We found no significant correlation between full-scale, verbal, and performance IQ and GFR. Unexpectedly, a significant positive correlation was found between mean "whole-life" WBC cystine levels and full-scale IQ $(R=0.68, P=0.007)$, verbal IQ $(R=0.57, P=0.033)$, and performance IQ $(R=0.73$, $P=0.003)$. Full-scale, verbal, and performance IQ were not different between patients having the homozygous $57 \mathrm{~kb}$ deletion and patients with other mutations.

\section{Discussion}

This study aimed at examining neurocognitive functioning in school-aged cystinosis patients treated with cysteamine starting at an early age in order to find evidence for clinically observed learning difficulties in this patient group. We found a poorer performance on visual-motor integration (VMI), sustained attention (Bourdon-Vos Test), visual memory (Rey's figure), planning (Rey's figure, drawing task), and motor speed (drawing task). The finding of a full-scale IQ just below the average with a relative good verbal IQ and poor performance IQ combined with poor executive functions is in line with the results of other international studies on neurocognitive functioning in children with cystinosis (Ballantyne et al. 1997; Colah and Trauner 1997; Spilkin et al. 2007, 2009; Ulmer et al. 2009; Williams et al. 1994; Wolff et al. 1982).

Interestingly, teachers reported more school problems than parents and patients $\geq 12$ years $(\mathrm{CBCL})$. It should be noted however that scores on the CBCL are slightly distorted in pediatric populations (Perrin et al. 1991). This 
J Inherit Metab Dis (2010) 33:787-793

791

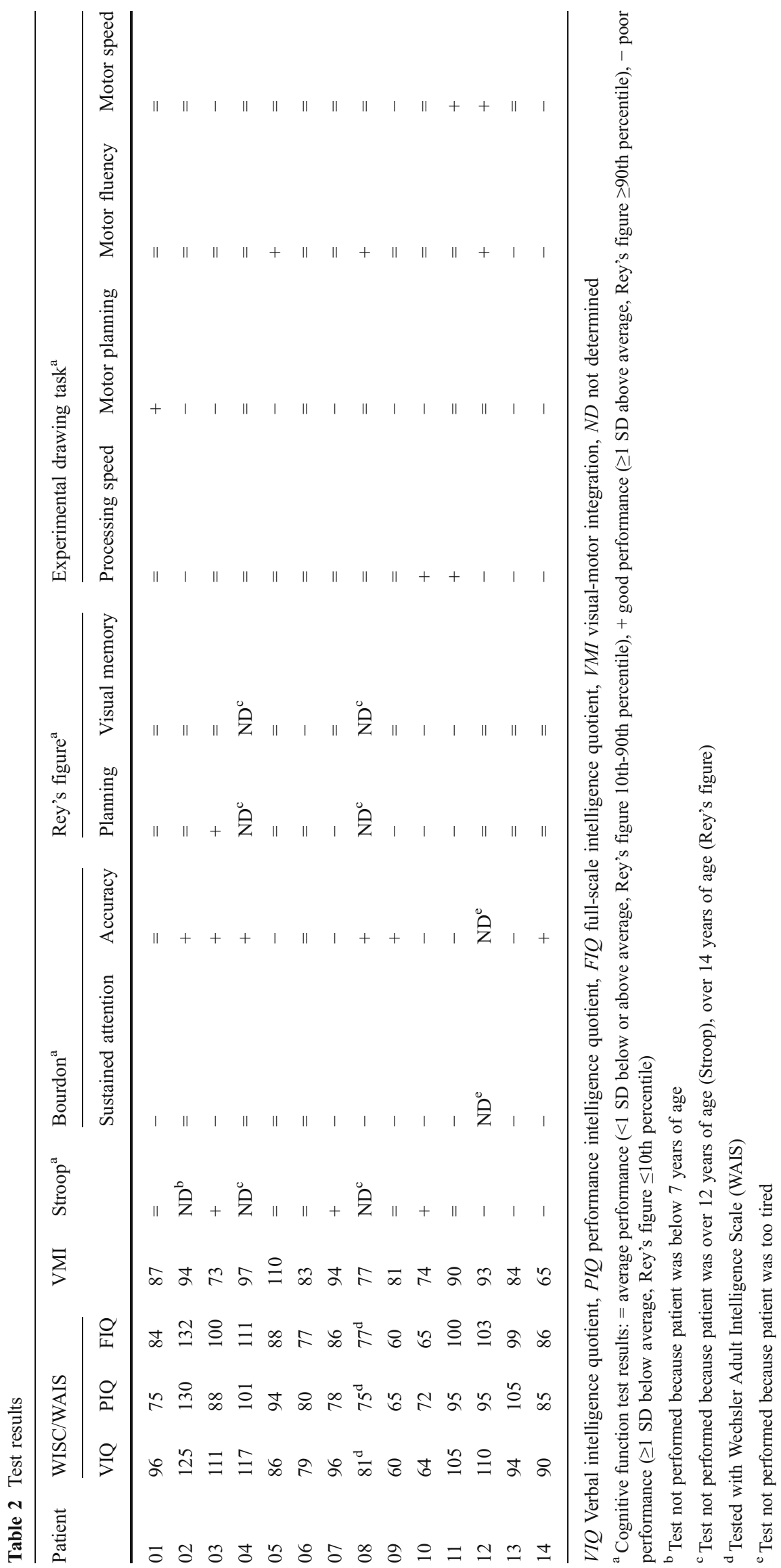

望 Springer 
is due to the fact that children suffering from a somatic disorder show an increased risk for overall adjustment problems, internalizing and (to a lesser extent) externalizing symptoms. Therefore, they are more likely to show higher scores on the scales of somatic complaints and internalizing problems when compared to their healthy peers (Lavigne and Faier-Routman 1992). It is known that patients over 12 years of age do not seem to recognize their emotional and learning difficulties (Delgado et al. 2005; Gipson et al. 2004), and it might be suggested that parents do not expect their children to have major school problems, since they seem to have a normal intelligence and in particular normal or even above normal verbal levels. A study using the CBCL conducted in 2005 on behavioral problems in children with cystinosis revealed more social problems in cystinosis patients compared to patients with another chronic disease (cystic fibrosis) and compared to healthy control subjects. However, in that study only the patients and their parents, and not the teachers, completed the checklists (Delgado et al. 2005). In our study, such behavioral problems were not reported.

A limitation of this study is the small study population, since cystinosis is a very rare disorder. We also found a broad heterogeneity in terms of general intelligence. On the other hand, the strength of this work lays in the broad pallet of standardized tests, which were adequately administered by a trained team of psychologists.

\section{Pathogenesis of neurocognitive disturbances in cystinosis}

The pathogenesis of brain involvement in cystinosis remains unclear. Thus far, three hypotheses have been postulated. These include progressive accumulation of cystine in brain cells (in particular oligodendrocytes), progressive development of intracranial microvascular disease, and alterations of the blood-brain barrier leading to cystine deposits within cerebral pericytes, thus making them unable to prevent circulating toxins from entering the central nervous system (Vogel et al. 1990).

A study performed on $\mathrm{ctns}^{-{ }^{--}}$knockout mice showed spatial short-term memory impairments, comparable to the cognitive anomalies found in cystinosis patients. The highest cystine levels were found in the hippocampus, cerebellum, and brainstem, respectively (Maurice et al. 2009). In human cystinosis patients, cystine accumulates in all parts of the brain, especially in the basal ganglia (Jonas et al. 1987). Whether cysteamine therapy is able to influence learning difficulties remains unclear. Our study failed to demonstrate a positive effect of cysteamine therapy, evaluated by "wholelife" WBC cystine levels, on neurocognitive functioning. In line with our results, it should be noted that the study by Wolff et al. conducted on patients not treated with cysteamine showed a similar pattern of normal general intelligence with relatively poor scores for performance IQ and relative good scores for verbal IQ (Wolff et al. 1982).

Interestingly, we found a positive correlation between WBC cystine levels and full-scale, verbal, and performance IQ results. This unexpected observation might be due to unknown side effects of cysteamine on brain function. Cysteamine is suggested to cross the blood-brain barrier as mixed disulfide with cysteine and is reduced in cerebro to free cysteamine. The administration of supraclincal doses of cysteamine $(250 \mathrm{mg} /$ $\mathrm{kg})$ to rats showed a remarkable increase in cerebral and cerebellar levels of methionine, and a drop in cerebral levels of cysteine and an anti-oxidant compound, S-(2-aminoethyl)-Lcysteine ketimine decarboxylated dimer (AECK-DD), probably due to the oxidative effect of cysteamine (Pinto et al. 2009). It cannot be ruled out that the administration of high cysteamine doses might have a detrimental effect on the brain. Studies of cysteamine metabolites in the spinal fluid of cystinosis patients might help to clarify pathways involved in cerebral cysteamine metabolism in humans and to identify eventual markers of cysteamine-induced damage. Unfortunately, we could not determine "whole-life" cysteamine dose in our patients because it was not always correctly noted in the patient's records, and we had no information about compliance. In an earlier study, a negative association was found between the variance in cystine levels and performance IQ (Bava et al. 2010); these findings should be further examined in larger patient populations and in $\mathrm{ctns}^{-/-}$mice treated with cysteamine.

In our study, patients with the homozygous $57 \mathrm{~kb}$ deletion had a general intelligence comparable to those with heterozygous mutations. This suggests that the absence of the CARKL gene, which is another gene removed in patients with homozygous $57 \mathrm{~kb}$ deletion (Wamelink et al. 2008), does not contribute to the cerebral dysfunction of cystinosis patients.

\section{Conclusion}

Neurocognitive diagnostics aimed at visual-motor integration, visual memory, planning, sustained attention, and motor speed are indicated in all cystinosis patients from the age of 7-8 years. Deficits in these fields can lead to learning difficulties in reading, spelling, and arithmetic. For instance, poor visual motor integration, motor speed, and sustained attention may prevent the child from recognizing letter forms, recalling and writing them, and from meeting the time constraints often involved in school assignments. Early neuropsychological diagnostics can contribute to early recognition from special education services, which might reduce the development of these learning problems and result into targeted remedial teaching. Parents and teachers should be informed that possible deficits or "minor symptoms" might not be attributed to the general effects of 
having a chronic disease. Further research on the etiology of specific deficits of neurocognitive functioning in schoolaged cystinosis patients is recommended.

Acknowledgements We would like to thank L. Nabuurs-Kohrman for her contribution to the neurocognitive testing of all patients and scoring of the results and the Dutch Kidney Foundation for their financial support.

Details of funding This study was funded by the Dutch Kidney Foundation. We state to be independent from this sponsor, the content of the manuscript was not influenced by the sponsor.

Open Access This article is distributed under the terms of the Creative Commons Attribution Noncommercial License which permits any noncommercial use, distribution, and reproduction in any medium, provided the original author(s) and source are credited.

\section{References}

Achenbach TM (1991) Manual for the child behavior checklist/4-18 and 1991 profile. University of Vermont, Department of Psychiatry, Burlington

Ballantyne AO, Scarvie KM, Trauner DA (1997) Academic achievement in individuals with infantile nephropathic cystinosis. Am J Med Genet 74:157-161

Bava S, Theilmann RJ, Sach M et al. (2010) Developmental changes in cerebral white matter microstructure in a disorder of lysosomal storage. Cortex 46:206-216

Beery KE (1997) The Beery-Buktenica VMI. Developmental test of visual-motor integration: administration, scoring, and teaching manual, 4th edn. Modern Curriculum, Parsippany, NJ

Bernstein JH, Waber DP (1996) Developmental scoring system for the Rey Osterrieth complex figure. Psychological Assessment Resources, Odessa

Colah S, Trauner DA (1997) Tactile recognition in infantile nephropathic cystinosis. Dev Med Child Neurol 39:409-413

Delgado G, Schatz A, Nichols S, Appelbaum M, Trauner D (2005) Behavioral profiles of children with infantile nephropathic cystinosis. Dev Med Child Neurol 47:403-407

Gahl WA, Thoene JG, Schneider JA (2002) Cystinosis. N Engl J Med 347:111-121

Gipson DS, Wetherington CE, Duquette PJ, Hooper SR (2004) The nervous system and chronic kidney disease in children. Pediatr Nephrol 19:832-839

Hammes JGW (1978) De Stroop Kleur-woord test, handleiding. Swets \& Zeitlinger, Lisse

Jonas AJ, Conley SB, Marshall R, Johnson RA, Marks M, Rosenberg H (1987) Nephropathic cystinosis with central nervous system involvement. Am J Med 83:966-970

Kort W, Schittekatte M, Compaan EL et al. (2002) Wechsler Intelligence Scale for Children, derde editie NL. Psychological Corporation, London

Lavigne JV, Faier-Routman J (1992) Psychological adjustment to pediatric physical disorders: a meta-analytic review. J Pediatr Psychol 17:133-157
Maurice T, Hippert C, Serratrice N et al. (2009) Cystine accumulation in the CNS results in severe age-related memory deficits. Neurobiol Aging 30:987-1000

Perrin EC, Stein RE, Drotar D (1991) Cautions in using the Child Behavior Checklist: observations based on research about children with a chronic illness. J Pediatr Psychol 16:411-421

Pinto JT, Khomenko T, Szabo S et al. (2009) Measurement of sulfurcontaining compounds involved in the metabolism and transport of cysteamine and cystamine. Regional differences in cerebral metabolism. J Chromatogr B 877:3434-3441

Schoemaker MM, Schellekens JMH, Kalverboer AF, Kooistra L (1994) Pattern drawing by clumsy children: a problem of movement control? In: Simner ML, Hulstijn W, Girouard PL (eds) Contemporary issues in the forensic, developmental and neurological aspects of handwriting. AFDE, Toronto, pp 45-64

Schwartz GJ, Munoz A, Schneider MF et al. (2009) New equations to estimate GFR in children with CKD. J Am Soc Nephrol 20:629637

Spilkin AM, Ballantyne AO, Babchuck LR, Trauner DA (2007) Nonverbal deficits in young children with a genetic metabolic disorder: WPPSI-III performance in cystinosis. Am J Med Genet B Neuropsychiatr Genet 144:444-447

Spilkin AM, Ballantyne AO, Trauner DA (2009) Visual and verbal learning in a genetic metabolic disorder. Neuropsychologia 47:1883-1892

Town M, Jean G, Cherqui S et al. (1998) A novel gene encoding an integral membrane protein is mutated in nephropathic cystinosis. Nat Genet 18:319-324

Trauner DA, Chase C, Scheller J, Katz B, Schneider JA (1988) Neurologic and cognitive deficits in children with cystinosis. J Pediatr 112:912-914

Ulmer FF, Landolt MA, Vinh RH et al. (2009) Intellectual and motor performance, quality of life and psychosocial adjustment in children with cystinosis. Pediatr Nephrol 24:1371-1378

Verhulst FC, Van der Ende J, Koot HM (1996) Handleiding voor de CBCL/4-18. Department for Child and Adolescent Psychiatry, Erasmus MC-Sophia Children's Hospital, Rotterdam

Verhulst FC, Van der Ende J, Koot HM (1997a) Handleiding voor de Teacher's Report Form (TRF). Department for Child and Adolescent Psychiatry, Erasmus MC-Sophia Children's Hospital, Rotterdam

Verhulst FC, Van der Ende J, Koot HM (1997b) Handleiding voor de Youth Self-Report (YSR). Department for Child and Adolescent Psychiatry, Erasmus MC-Sophia Children's Hospital, Rotterdam

Vogel DG, Malekzadeh MH, Cornford ME, Schneider JA, Shields WD, Vinters HV (1990) Central nervous system involvement in nephropathic cystinosis. J Neuropathol Exp Neurol 49:591599

Vos PG (1998) Bourdon Vos test, handleiding. Swets \& Zeitlinger, Lisse

Wamelink MM, Struys EA, Jansen EE et al. (2008) Sedoheptulokinase deficiency due to a $57-\mathrm{kb}$ deletion in cystinosis patients causes urinary accumulation of sedoheptulose: elucidation of the CARKL gene. Hum Mutat 29:532-536

Wechsler D (1991) Wechsler intelligence scale for children, 3rd edn. Psychological Corporation, San Antonio

Williams BL, Schneider JA, Trauner DA (1994) Global intellectual deficits in cystinosis. Am J Med Genet 49:83-87

Wolff G, Ehrich JH, Offner G, Brodehl J (1982) Psychosocial and intellectual development in 12 patients with infantile nephropathic cystinosis. Acta Paediatr Scand 71:1007-1011 